\title{
Ética ambiental no Brasil: história, campo de estudos e militância: entrevista com Luciano Félix Florit
}

\section{Por Samira Feldman Marzochi'}

O professor e pesquisador Luciano Félix Florit, convidado a conversar sobre sua pesquisa em Ética Socioambiental, é autor de inúmeros artigos acadêmicos sobre o tema e do livro "A Reinvenção Social do Natural: natureza e agricultura no Mundo Contemporâneo" (Edifurb, 2004). Atualmente, Florit se dedica ao problema da consideração moral de seres vivos não humanos, entre outras questões relacionadas à ética socioambiental, valoração e desenvolvimento regional. É professor do Programa de Pós-Graduação em Desenvolvimento Regional da Universidade de Blumenau, graduado em Sociologia pela Universidad de Buenos Aires (1995), mestre em Sociologia Política pela Universidade Federal de Santa Catarina (1998), doutor em Sociologia pela Universidade Federal do Rio Grande do Sul (2003) e pós-doutorado em Antropologia pela Universidade Federal de Minas Gerais (2017).

Nesta entrevista, o pesquisador argumenta que o grande desafio dos estudos em ética socioambiental "é conceber abordagens que mostrem em que medida as questões dos seres não humanos e as iniquidades socioambientais estão relacionadas, e fazer isto sem abandonar uma perspectiva ético-política que inclua o elemento normativo". Para ele, "dificilmente teremos relações propriamente dignas entre seres humanos enquanto considerarmos os seres não humanos como

1 Departamento e Programa de Pós-Graduação em Sociologia da Universidade Federal de São Carlos (UFSCar) - São Carlos - Brasil - marzochi@gmail.com 
meras coisas", assim como "também não teremos relações realmente amorosas com os seres não humanos no contexto da exploração entre seres humanos".

\section{Luciano, gostaria de iniciar esta entrevista perguntando-the como foi que você se aproximou do campo de estudos em Ética Ambiental.}

Esta aproximação teve duas facetas: uma de caráter acadêmico formal e outra mais associada aos percursos existenciais, uma alimentando a outra, digamos assim. No aspecto acadêmico, foi uma decorrência do ponto a que cheguei com meu trabalho de tese que resultou no livro "A reinvenção social do natural: natureza e agricultura no mundo contemporâneo". Nele, analiso a radicalização da manipulação da natureza em várias frentes, e os riscos que ela tem gerado, provocando uma situação de ansiedade generalizada cuja resposta são os movimentos de "volta ao natural". Esta seria uma tentativa de encontrar um refúgio, uma segurança, mas ela nunca se consuma completamente porque a manipulação da natureza já criou uma situação sem retorno. Por isso, há uma ameaça constante à nossa segurança ontológica, o senso básico de continuidade do que somos num mundo previsível.

Esses movimentos são diversos. Há aqueles de tendência mais fortemente ideológica (no sentido de falsa consciência), resposta típica da sociedade urbana industrial capitalista, e há aqueles que se engajam numa construção da natureza, reinventando-a, de um modo que é direcionado por valores e premissas ético-políticas. Estes, em geral, questionam profundamente o padrão de desenvolvimento associado às monoculturas, transgênicos e uso exacerbado de agrotóxicos, à submissão dos pequenos produtores em cadeias industriais etc. Assim, passei a perceber duas coisas: por um lado, que estamos fatalmente imputando valores e julgamentos morais ao discutirmos a relação com a natureza e os seres vivos não humanos (isto, na verdade, é patrimônio antigo da antropologia cultural, mas tem cobrado uma nova dimensão no contexto da sociedade de risco, de incerteza fabricada, de mudanças climáticas ou do antropoceno, como queiramos chamar) e, por outro, que estes processos de atribuir valor não são suficientemente refletidos em escala pública, embora sejam cruciais no enfrentamento dos dilemas morais contemporâneos.

Percebi que a discussão propriamente ética com relação à natureza vinha sendo escondida e escamoteada por trás da métrica monetária de atribuir valor às coisas, e que havia um acúmulo de reflexão filosófica que, por diversas razões, não estava sendo suficientemente mobilizado para a reflexão social. $\mathrm{O}$ primeiro locus no qual me adentrei para tentar juntar as coisas foi a criação e 
abate industrial de animais, que é uma atividade muito forte em Santa Catarina (estado em que moro) e com relação à qual a reflexão social crítica estava totalmente blindada por naturalizações e justificativas claramente inconsistentes. Esta compreensão foi ficando clara enquanto concluía aquele trabalho. Por isso, o encerrei com a seguinte frase: "No plano ético, o fato da vida ser ou não natural é totalmente irrelevante".

De fato, um porco de uma granja industrial é resultado de uma manipulação humana imensa; eles não são nada "naturais", e mesmo assim o que acontece com eles nos diz respeito. Nesse momento, percebi também que havia um elemento fortemente ligado ao território. Embora estejamos falando de uma questão que tem um caráter civilizacional, ela aparece com características definidas e identificáveis geograficamente. Ao mesmo tempo em que na Europa se discutia o reconhecimento da senciência dos animais de produção, em Santa Catarina planejava-se o aumento e a concentração da produção como se esta questão não existisse.

De fato, no Brasil existe, aparentemente, um descompasso cada vez mais acentuado entre a "consciência ecológica" e as práticas políicas e econômicas. De que modo explicá-lo? Este descompasso aparece, também, em outros países?

Este descompasso não é exclusivo do Brasil, mas aqui assume características peculiares em função da sua configuração histórica e territorial, sua posição na divisão internacional do trabalho, e o processo político em curso. O Brasil é um país megadiverso, tanto em termos de biodiversidade, como de sociodiversidade. Não obstante, o peso político e econômico dos grandes conglomerados urbanos ofusca, de diversas formas, o reconhecimento dessa riqueza. Por outro lado, a pauta econômica, desproporcionalmente apoiada em recursos primários, cria mais uma barreira para que este descompasso seja superado. As concepções predominantes de desenvolvimento não têm conseguido incorporar a questão ecológica de modo consistente com um projeto de país de longo prazo. Embora com nuances diferentes, esta dificuldade se observou nos períodos de políticas desenvolvimentistas e se observa agora, em que as pautas mais puramente neoliberais vêm se impondo.

Um Estado é sempre uma entidade recheada de contradições, mas penso que elas têm sido exageradamente grandes e longas no caso do Brasil. Uma forma de explicar estas contradições é considerando as diversas escalas territoriais em que acontecem as decisões e os impactos. Pensemos, por exemplo, na política energética. Do ponto de vista do país como um todo, constrói-se 
o argumento de que as hidroelétricas contribuem para uma matriz energética "limpa". No entanto, se você analisa do ponto de vista da escala local, você passa a ver com clareza que essa "limpeza" não é a tal. Pensemos, por exemplo, em Belo Monte. Vendo o que acontece localmente, percebe-se que a região foi escolhida como "zona de sacrifício". Há a imposição de um dano à natureza e às comunidades tradicionais que vivem no Xingu que é justificado em virtude dos benefícios que outros sujeitos, não locais, irão obter. Ocorre que esses outros sujeitos são muito poderosos (como certas indústrias) ou são muito numerosos (os eleitores das grandes cidades). A escolha da zona de sacrifício é extremamente racional, assim como extremamente perversa.

Pensemos, agora, na situação dos povos e comunidades tradicionais que enfrentam uma situação ainda mais grave no contexto político atual. Refiro-me aos povos indígenas, mas também aos diversos grupos que lutam por continuar seus modos de vida em relação direta com a natureza, e com fraca integração ao mercado, como quilombolas, ribeirinhos, caiçaras, geraizeiros, vazanteiros, extrativistas dos mais diversos, povos da floresta etc. Eles enfrentam contínuas ameaças territoriais, sejam por grilagem, por falta de ação pública, por estarem "cercados" por monoculturas ou por outras formas de violência física e simbólica. Não há dúvida de que a continuidade desses modos de vida é algo muito positivo para o Brasil, em geral, e também muito estimulante para a população urbana sensível com as questões ambientais. Sua mera existência presta serviços enormes, do ponto de vista ecológico, do ponto de vista da soberania alimentar e do ponto de vista simbólico, porque mantém, na prática, usos da natureza que não passam pela redução instrumental. Não obstante, os dramas locais pouco são percebidos pelas populações urbanas que, mesmo inadvertidamente, dão fôlego a quem violenta esses povos. Isso acontece porque é justamente nossa territorialidade urbana-industrial-capitalista descontrolada que constitui a eles uma ameaça.

É por tudo isso que a "consciência ecológica" precisa de uma leitura territorial, que é justamente o que é ignorado pelos discursos exclusivamente técnicos e pelo senso comum ecológico. Penso que, se o consumo "consciente" passasse a ser um consumo "territorialmente consciente", já seria um avanço.

\section{Como você definiria, então, o conceito de "ética ambiental"?}

De modo geral, a ética ambiental pode ser definida como o campo de reflexão crítica sobre os valores por meio dos quais estabelecemos as relações com a natureza e os seres vivos não humanos. Esta definição inclui as paisagens 
silvestres e os elementos que as compõem, mas também inclui os seres que são resultados de manipulação antrópica. Acho que a ética animal deve ser vista como um ramo da ética ambiental, incluindo aqui a questão do tratamento de animais silvestres e domesticados. Este seria o campo da reflexão ética propriamente dito. É importante aqui estabelecer a distinção com outro tipo de fenômeno, que é o da reprodução social de valores morais. Enquanto a reflexão ética é uma atividade filosófica, a reprodução de valores morais é um fenômeno social, inteligível pela análise sociológica, antropológica e política. É claro que se trata de aspectos que na vida social se inter-relacionam, mas é importante perceber que rementem originalmente a domínios diferentes.

Dito isto, posso explicar o que, me parece, deve ser entendido por ética socioambiental, que é, de fato, o cerne do que estou tentando fazer. No meu entendimento, a ética socioambiental é o campo de reflexão que faz uma interface entre a ética ambiental e os estudos sociais das iniquidades ambientais. No plano analítico, implica estudar as relações sociais que resultam na desconsideração moral da natureza e dos seres vivos não humanos, o que, no contexto contemporâneo, tendemos a chamar de coisificação ou objetificação. No plano normativo, implica em conciliar a consideração moral desses seres vivos com a afirmação da justiça ambiental entre seres humanos.

É claro que esta definição implica assumir o risco de lidar com uma série de assuntos colaterais que tornam o percurso bastante espinhoso. Há uma quantidade de questões difíceis que passam a se colocar quando um sociólogo encara estas questões. Há o perigo de incorrer em essencialismos, em visões românticas e até elitistas. Também há o problema da divisão do trabalho disciplinar (e também político!), que coloca os preocupados com a natureza e não humanos de um lado, e os preocupados com as desigualdades sociais de outro, ambos ancorados em olhares antropocêntricos, nem sempre problematizados. E também há a dificuldade em conectar uma reflexão eminentemente normativa (que se pergunta como as coisas deveriam ser) com uma análise que leve em conta as relações sociais (que ajude a explicar por que as coisas são como são).

Penso que o grande desafio é conceber abordagens que mostrem em que medida as questões dos seres não humanos e as iniquidades socioambientais estão relacionadas, e fazer isto sem abandonar uma perspectiva ético-política que inclua o elemento normativo. Seria mais simples se assumíssemos um relativismo descompromissado ou uma suposta neutralidade, mas, de fato, o padecimento a que são submetidos incontáveis seres em virtude de decisões humanas é algo ao qual é importante nos abrir para incluí-lo em nossa lista de problemas insuportáveis, junto à aberrante desproporcionalidade com que 
são distribuídos os ônus ambientais, prejudicando, especialmente, os grupos sociais mais vulneráveis. Por outro lado, a causalidade dos problemas que são objeto de reflexão por parte da ética ambiental é algo que precisa ser explicado, assim como já assumimos que precisa ser explicado como é que se geram as iniquidades sociais.

\section{Os movimentos ambientalistas tiveram um papel importante na conformação deste campo de estudos?}

O ambientalismo é um movimento complexo que tem passado por transformações muito profundas. De modo geral, é possível dizer duas coisas: por um lado, houve uma sensibilidade razoavelmente desenvolvida com relação a questões propriamente éticas relativas a reconhecer valores intrínsecos na natureza. Esta sensibilidade, embora não tenha desaparecido, ficou relegada em prol de agendas mais pragmáticas que foram assumidas na medida em que $o$ ambientalismo foi assumindo a modernização ecológica como forma de existir institucionalmente. $\mathrm{O}$ ônus disto tem sido grande, pois, assim, o ambientalismo renuncia a aspectos importantes da reflexão crítica que é capaz de promover, que é civilizatória e também sociopolítica.

Por outro lado, as perspectivas mais socioambientais vêm aprofundando suas lutas, associando a defesa da biodiversidade à defesa da sociodiversidade. Isso é importante e tem sido um movimento estratégico. A meu ver, é por aqui que a retomada da discussão sobre a ética ambiental (ou socioambiental, como eu prefiro dizer) deve acontecer. Isto porque é na sociodiversidade que há múltiplas valorações da natureza e dos seres não humanos que confrontam a redução instrumental que é hegemônica. Estas múltiplas valorações são riquíssimas. Elas têm uma enorme complexidade e, ao mesmo tempo, estão associadas a modos de vida concretos que são capazes de providenciar subsistência e sentido a muitos grupos sociais. Elas são muito importantes porque representam formas de ver e se relacionar com o mundo que não são redutíveis aos dualismos típicos dos paradigmas ocidentais, urbanos industriais. Refiro-me, por exemplo, ao dualismo valor intrínseco/ valor instrumental e ao tradicional natureza/ cultura.

A cultura urbano-industrial, quando moraliza a natureza e os seres vivos, tende a fazê-lo incorporando-os ao universo moral antropocêntrico, condenando todo o resto à coisificação. $\mathrm{O}$ caso dos animais domesticados é emblemático. De um lado, os pets e, do outro, os porcos das granjas industriais, dois universos tão contrapostos quanto os dos humanos e das coisas. Já as valorações dos povos tradicionais (indígenas, povos da floresta, quilombolas, 
geraizeiros etc.) têm algo muito importante a nos dizer neste sentido: que um modo de viver dependente da natureza (ou seja, todos os modos de viver!!!) precisa saber fazer uso dela sem, no entanto, tratá-la como uma coisa, como um objeto intercambiável como qualquer outro insumo fabricado por alguém. Esta mensagem é imensa. Ela nos sugere que o valor monetário é apenas uma métrica que é cega para muitos tipos de valores que a natureza pode representar na consciência. Também nos mostra como é que se chega à uma situação em que pode haver um uso da natureza que seja autocontido em função de critérios de valor, em contraposição ao modelo expansionista próprio da lógica capitalista.

Mas isto não quer dizer que algo assim seja fácil para o socioambientalismo. Muitas vezes, o olhar antropocêntrico também se reproduz no seio das suas lutas. Há várias razões que explicam isso... Algumas são epistemológicas, outras têm a ver com uma avaliação das prioridades num contexto onde a violência é muito presente. Às vezes, pode até parecer diletante apresentar uma reflexão sobre o valor que reconhecemos nos seres não humanos quando a violência contra seres humanos é a linguagem da disputa. A ética trabalha com argumentos, e as lutas sociais têm a ver também com enfrentar relações de poder. E nas lutas ambientais, hoje, o poder se vale das mais brutais formas de violência. Contudo, penso que os argumentos são da maior importância, pois por meio deles é possível fazer com que a luta dos povos tradicionais passe a fazer sentido, também, para setores urbanos.

Em que situações a militância ambientalista pode entrar em conflito com a ciência ambiental?

Prefiro a expressão "saberes ambientais" à de "ciência ambiental". O modelo naturalista de ciência traz embutido uma representação muito peculiar da natureza e do ambiente que não pode ser tomada como algo dado, sem problematizações. Em geral, muitos dos cientistas que atuam no campo das ciências ambientais (no plural) sabem bem disso. Então, a militância ambientalista, como qualquer militância, pode ter dificuldades em combinar sua ação com um olhar que não se limite a reificações ou essencialismos. Mas, embora esta seja sempre uma questão desafiadora, tenho a impressão de que a militância, hoje, tem um grau de reflexividade que não a deixa cair tão facilmente nessas armadilhas.

Há, contudo, as dificuldades que são consequências da divisão do trabalho acadêmico. Por exemplo, a atitude do "preservacionismo sem gente", que 
assume que essa visão dicotômica natureza intocada/sociedade depredadora ainda está presente, em boa medida como consequência de formações acadêmicas dissociadas. Isso é um problema porque dificulta pensar de forma integrada o que é essencial: o cuidado com o ambiente "natural" concomitante com a equidade social.

Na militância animalista, esse problema também aparece, com suas características próprias, de um modo que me soa emblemático: com a divisão de trabalho entre os preocupados com animais silvestres e os preocupados com os domesticados. Em geral, esta clivagem decorre de concepções éticas e conceitos biológicos diferenciados que, naturalizados, continuam a fazer seu trabalho segregador. Fundamentalmente, o problema aqui é o reconhecimento de valor moral aos animais enquanto indivíduos (o que, geralmente, subsidia as lutas animalistas) e o valor ecológico das espécies (que informa a preocupação com os animais silvestres e se apoia em argumentos holistas). Muito bem, aqui há uma série de questões éticas bastante relevantes e difíceis, como quando o valor da espécie orienta a sacrificar (ou deixar de prestar socorro) a um indivíduo em função do bem da espécie, por exemplo.

Mas, para além desses espinhosos problemas éticos, o que se observa é que essa clivagem cria uma segregação das lutas sociais bastante nociva, que é a separação entre animalistas e ambientalistas. Vejo isso com preocupação porque implica falta de identificação do núcleo duro do problema, que é a transformação da natureza com fins exclusivamente instrumentais. As áreas silvestres são santuários protegidos desta transformação, o que é feito a partir de um olhar tipicamente urbano-industrial. Do outro lado, os bilhões de animais coisificados na pecuária industrial são, talvez, o exemplo mais acabado de aonde essa transformação com fins exclusivamente instrumentais pode levar. É de se observar, aqui, que quando se fala da pecuária industrial, estamos falando de seres sencientes, com sensações, memória, inteligência etc. e, em muitos casos, de mamíferos muito próximos de nós. Tratá-los como mero insumo de um processo industrial não é algo trivial. Mas, como estão as coisas hoje, parece que essa manipulação radical de seres não humanos, que já foram silvestres, não faz muito parte do problema da agenda ambientalista, a menos que sejam causa de degradação ambiental no sentido estrito, como no caso do desmatamento associado à pecuária e à poluição hídrica gerada pela suinocultura.

Então, não é tanto que a militância possa entrar em conflito com a ciência ambiental. O que vejo, pelo contrário, é que a militância, às vezes, é refém de clivagens científicas, mas de uma ciência que ainda carrega as grandes dicotomias humano/ animal, cultura/ natureza, o que impede a construção 
de saberes necessários para enfrentar os dilemas éticos socioambientais que temos pela frente.

Por um lado, a militância tende a acompanhar a ciência; por outro, ela também pressiona a ciência para que responda a problemas éticos. A partir de que momento a questão da natureza como sujeito de direitos passa a ser incorporada às discussões sobre ética socioambiental?

Há dois grandes movimentos que confluem neste sentido. Por um lado, tem o movimento animalista que, no plano ético, tem tido uma incidência extraordinária, apesar de que enfrenta um dos problemas mais difíceis e insidiosos da sociedade contemporânea. Cabe ressaltar, aqui, que nem todas as argumentações animalistas resultam na defesa de direitos propriamente ditos. Algumas propõem a consideração moral dos animais não humanos sem, no entanto, colocá-los como sujeitos de direito. Por outro lado, os avanços neste sentido vêm sendo progressivos, embora ambivalentes. A ambivalência decorre de que o que vem acontecendo é o reconhecimento da senciência dos animais, sua capacidade de ter sensações, sofrer etc. Embora isto tenha implicações práticas em termos de cuidados e bem-estar, não significa, propriamente, o reconhecimento de direitos. No Brasil, no código civil, os animais continuam constando como "propriedade se movente" (que se move por si mesma, diferentemente dos bens imóveis e dos bens móveis), o que denota a continuidade de uma tipificação na forma de coisa, ou seja, meramente instrumental.

Mas as coisas não param por ali, porque a reflexão no campo jurídico é intensa, e há investigação constante, no sentido de encontrar analogias ou outras formas indiretas de garantir alguns direitos, como direito à vida e ao não sofrimento. Contudo, no arcabouço jurídico ocidental, desde Kant, a dignidade é atribuição exclusiva dos seres humanos. Isto significa dizer que só os humanos poderiam ser considerados fins em si mesmos, o que, por sua vez, significa que a todos os outros seres o destino que lhes cabe é servir instrumentalmente aos humanos. Estas questões se apoiam em fundamentos filosóficos e jurídicos que estão também alinhados com concepções religiosas no ocidente. Falo isso porque, há poucos anos, tivemos a publicação da Encíclica Laudato Si, do Papa Francisco. Embora com alguns séculos de atraso, ela modera a concepção antropocêntrica do catolicismo e firma uma posição teológica muito mais razoável, na qual os seres humanos são corresponsáveis no cuidado de todos os seres 
vivos da "criação". A meu ver, trata-se de um documento muito relevante que deverá ter efeitos significativos em médio prazo.

Por uma via diferente, há um movimento de reconhecimento de direitos da natureza apoiado, agora, não numa matriz ocidental de pensamento, mas nas filosofias tradicionais dos povos originários da América. Esta posição faz parte da perspectiva do bem-viver dos povos andinos e está associada ao movimento do novo constitucionalismo na América Latina. A ideia central, conforme consta na Constituição do Equador, é que a Natureza ou Pachamama passa a ter o direito de ser preservada, e inclusive de ser restaurada, em virtude de seu valor intrínseco. Ao que tudo indica, este dispositivo poderá ter eficácia para proteger entes, como um rio, uma montanha, unidades de paisagem etc.

Trata-se, portanto, de uma abordagem holista do valor intrínseco que é reconhecido, porque se aplica a entidades que são compostas por muitos entes individuais. Há quem veja isso com muita esperança, porque enxerga um caminho para resolver a crise ambiental. A meu ver, esta posição realmente oxigena as coisas, mas também não está livre de contradições e tensões. Por um lado, é uma ideia que vai no caminho de afirmar os direitos territoriais de povos historicamente subalternizados.

Quero dizer, há sujeitos concretos que dão suporte à essa perspectiva, e esses sujeitos têm muitíssimo a contribuir na ordem de construção de uma ética socioambiental, conforme a defini há pouco. Há também uma alternativa às dicotomias ocidentais a que também me referi antes, que são verdadeiras armadilhas epistemológicas para uma ética socioambiental. No entanto, ao se firmar numa posição holista, acaba não havendo muito a dizer com relação aos seres vivos não humanos enquanto indivíduos. Tenho a impressão de que é justamente isso que explica por que, na Constituição do Equador, os animais são mencionados apenas no capítulo sobre segurança alimentar, ou seja, reduzidos à uma condição meramente instrumental.

A crise ambiental, na América Latina, certamente está relacionada ao que é feito com montanhas, rios e florestas; mas, também, está relacionada ao fato do Brasil ser o maior exportador de carne do mundo, e os direitos holistas da natureza não nos ajudam de forma direta nisso. Ocorre, também, que a função de uma ética socioambiental não se resume a ajudar a resolver uma "crise ambiental" como a entendemos. Isso porque há coisas que podem ser inaceitáveis mesmo não sendo fator direto de degradação ecológica, mas por razões morais. Uma parte expressiva da questão animal passa por aí. Por isso, penso que tanto uma ética socioambiental como uma concepção jurídica de direitos 
estendida a seres não humanos carecem de uma elaboração intercultural e, embora sejam necessárias para equacionar a crise ambiental, seu papel seria muito mais abrangente.

Luciano, de que modo você contextualizaria a institucionalização acadêmica dos estudos sobre ética ambiental no Brasil e no mundo?

Posso passar algumas impressões. A ética é, disciplinarmente falando, entendida como objeto de trabalho dos filósofos. Entre os filósofos, a ética ambiental e animal tem ocupado um lugar de algo subordinado, não contabilizado no centro das grandes questões. Progressivamente, no entanto, foi ganhando espaço, na medida em que houve mais e mais questões sérias colocadas pela realidade social, e autores muito competentes e corajosos assumindo estas questões.

Contudo, penso que a consolidação da ética ambiental, como objeto da filosofia, se ocorrer nos termos da estrita divisão do trabalho acadêmico, não será suficiente. É que a ética socioambiental implica lidar não apenas com argumentos normativos, mas também com relações de poder. E o poder não se curva aos argumentos. Precisamos, por um lado, refinar o nosso entendimento e descobrir as melhores razões que indicam como deveríamos agir com relação à natureza nos diferentes contextos em que nos encontramos. Isso é fundamental, e faz parte de um exame filosófico especulativo. Mas não é suficiente. Esse trabalho reflexivo e especulativo precisa ser combinado à análise das relações de poder concretas. Precisa-se examinar a conexão entre valores defensáveis e poder, ou seja, de um lado, identificar os bons argumentos éticos e examinar como conectá-los às forças para defendê-los. De outro lado, é necessário dissecar os argumentos falaciosos e entender por que, por vezes, são tão eficazes.

Em outras palavras, trata-se de construir uma interface entre filosofia e ciência social para examinar as disputas no campo dos valores ambientais. Essas disputas acontecem no terreno dos argumentos e no terreno do território; são disputas de palavras e também de força física, econômica e política. O Brasil de hoje é um palco tristemente claro de como os argumentos podem ser atropelados, sem a menor cerimônia, pela imposição interessada de olhares adulterados e fictícios (penso, especialmente, na promiscuidade entre o poder executivo e o parlamento que, supostamente, seria arena de argumentos). Mas, ainda assim, um senso ético não pode desistir de se apoiar em argumentos, e um senso de responsabilidade política não pode desistir de dar força social aos bons argumentos. 
Por outro lado, a interface entre filosofia e ciências sociais para a ética socioambiental não para por aí. Nas cosmovisões outras, que não a urbano-industrial-capitalista, elaboraram-se boas razões para justificar por que tratar a natureza do modo como é tratada por elas. E se considerarmos que, muitas vezes, elas também são fundamento de regras de uso mais sustentáveis do que as nossas, então há algo ali do qual é possível aprender. Não se trata, na maioria das vezes, de argumentações éticas formalizadas, mas de moralidades construídas em contextos de relação com a natureza e o território onde seres humanos e não humanos convivem em arranjos viáveis que perduram há séculos e resultam em ambientes bastante preservados.

Portanto, há uma leitura dessas relações sociais que pode ser feita no intuito de elucidar problemas éticos que enfrentamos. Para mim, o principal elemento que encontrei até o momento é que nessas moralidades o uso da natureza não está associado a uma redução instrumental e, portanto, é suscetível de ser regulado por critérios de valor moral. Isto, que é algo quase trivial do ponto de vista das moralidades ambientais desses povos, é uma inovação intelectual no contexto do debate estruturado pela clivagem moralização versus coisificação, ou valor intrínseco versus valor instrumental.

Então, voltando à institucionalização acadêmica, penso que este nexo interdisciplinar ainda precisa ser estabelecido e reconhecido. É um ponto de interseção entre a as ciências sociais (provavelmente, de início, com maior ênfase por parte da antropologia, mas que deveria abranger uma reflexão sociológica e política) e a filosofia, que não tem nada a ver com a chamada filosofia social e, muito menos ainda, com a construção de uma moralidade sociológica.

Mas há também reflexões muito vivas entre colegas que atuam no campo do direito. Surpreendentemente, é lá, me parece, que as questões do valor da vida de seres não humanos levam a reflexões que podem ter repercussões mais abrangentes. Parece-me que o próprio direito está, pelo menos na esfera acadêmica, bastante aberto a refletir sobre o impacto de cosmovisões e normatividades não dominantes.

Penso que à sociologia dos conflitos socioambientais e à sociologia ambiental, em geral, cabe ainda um papel muito relevante nesta problemática, evidenciando como as iniquidades ambientais e as disputas por recursos e território têm, também, uma dimensão que consiste em choques de valoração, nos quais os mais fracos nas relações de força são, por vezes, os mais fortes no terreno dos argumentos. Uma percepção clara disso pela sociedade envolvente é fundamental para encontrar caminhos que permitam a equidade socioambiental junto à ampliação da consideração moral para além dos humanos. Este é, ao fim das contas, o principal motivo desta discussão. 
Chegamos, então, ao ponto de maior interesse nesta entrevista. Você considera que as pesquisas em ética ambiental nos obrigam a rever, necessariamente, os paradigmas iluministas e humanistas?

Sim e não. Os paradigmas iluministas e humanistas constituem, evidentemente, limites para a construção de concepções capazes de integrar humanos e não humanos numa esfera moral, sobretudo quando assimilados de forma dogmática. No limite, precisam, sim, ser revistos, reconhecendo validade das diversas formas de conhecer a realidade e de imputar valor às coisas. Mas sou cauteloso quanto a isso, porque me parece que há muito a ser feito, ainda, com um bom uso da razão e reconhecendo o papel do ser humano enquanto alguém interdependente de outros seres.

Reconhecer valor intrínseco na vida de seres não humanos não necessariamente implica reconhecer igual valor à vida de todos os seres. $\mathrm{O}$ maior problema é o antropocentrismo obtuso e não todo tipo de antropocentrismo. O que quero dizer com isso é que alguém não precisa, necessariamente, abrir mão de todas as suas concepções metafísicas mais arraigadas para ter uma atitude generosa e compassiva com os outros, sejam eles quem forem. Valendo-me de uma expressão que ouvi de um velho amigo, "se for fazer faxina numa casa fechada há décadas, não comece com a flanela”: certamente, à medida que a faxina for avançando, chegará o momento em que a flanela será essencial, mas, até lá... Falo isso em termos muito práticos, o que não implica negar que a pesquisa e a reflexão devam ser incisivas e implacáveis com as amarras que nos afundam, mesmo parecendo confortáveis.

Certamente, cuidar bem dos seres não humanos não significa cuidar menos dos humanos. Pelo contrário, tudo indica que o que acontece, de fato, é o oposto. Cuidar de seres não humanos é próprio de sociedades que também sabem cuidar de humanos. Por isso, se o humanismo nos encoraja a sermos realmente solidários com as gerações presentes (e aí, sim, por consequência, as gerações futuras serão atendidas, e não o inverso), então esse humanismo nos levará a zelar pelos seres não humanos.

Por outro lado, parece claro que a degradação ecológica mais brutal está sempre associada à redução instrumental da natureza e dos seres. Na medida em que outras formas de reconhecer valores na natureza colocarem limites morais ao uso das paisagens e dos seres vivos, então estaremos dando passos seguros na direção de responder à degradação ecológica. Dificilmente teremos relações propriamente dignas entre seres humanos enquanto considerarmos os seres não humanos como meras coisas. Por outro lado, também não teremos 
relações realmente amorosas com os seres não humanos no contexto da exploração entre seres humanos.

Recebido em 07/02/2018

Aprovado em 29/05/2018

\section{Como citar esta entrevista:}

MARZOCHI, Samira Feldman. Ética ambiental no Brasil: história, campo de estudos e militância: entrevista com Luciano Félix Florit. Contemporânea - Revista de Sociologia da UFSCar, v. 8, n. 1, jan.- jun. 2018, pp. 343-356. 